\title{
Les oiseaux chanteurs. Sciences, pratiques sociales et représentations en Europe du Moyen Âge à nos jours
}

Glux-en-Glenne, du 4 au 6 avril 2012

\section{Corinne Beck et Martine Clouzot}

\section{(2) OpenEdition \\ Journals}

Édition électronique

URL : https://journals.openedition.org/cem/12054

DOI : $10.4000 /$ cem. 12054

ISSN : 1954-3093

\section{Éditeur}

Centre d'études médiévales Saint-Germain d'Auxerre

Édition imprimée

Pagination : 00

ISSN : 1623-5770

\section{Référence électronique}

Corinne Beck et Martine Clouzot, « Les oiseaux chanteurs. Sciences, pratiques sociales et

représentations en Europe du Moyen Âge à nos jours », Bulletin du centre d'études médiévales d'Auxerre I BUCEMA [En ligne], 15 | 2011, mis en ligne le 26 mars 2013, consulté le 22 septembre 2022. URL :

http://journals.openedition.org/cem/12054 ; DOI : https://doi.org/10.4000/cem.12054

Ce document a été généré automatiquement le 22 septembre 2022.

\section{cc) (†) (-)}

Creative Commons - Attribution - Pas d'Utilisation Commerciale - Partage dans les Mêmes Conditions 4.0 International - CC BY-NC-SA 4.0

https://creativecommons.org/licenses/by-nc-sa/4.0/ 


\section{Les oiseaux chanteurs. Sciences, pratiques sociales et représentations en Europe du Moyen Âge à nos jours}

Glux-en-Glenne, du 4 au 6 avril 2012

Corinne Beck et Martine Clouzot

1 «Les oiseaux chanteurs » est un projet pluridisciplinaire, transversal et international, initié et porté par l'UMR 5594 ARTeHIS de l'université de Bourgogne et l'UMR Calhiste de l'université de Valenciennes. Ce projet consiste à élargir une thématique déjà étudiée par les ornithologues, les éthologues, les littéraires et les musicologues, à d'autres disciplines a priori éloignées, dont les problématiques centrales touchent essentiellement aux domaines des sciences du vivant, de l'environnement et des sciences humaines et sociales. L'objet de recherche étant commun aux sciences de l'homme et de la société dans les champs de l'anthropologie, des sciences du vivant et des neurosciences, la période retenue s'inscrit donc dans la longue durée en allant du Moyen Âge à nos jours. Le projet est initié et porté par deux médiévistes : Corinne Beck (université de Valenciennes) et Martine Clouzot (université de Bourgogne).

\section{Opportunité de ce colloque scientifique, interdisciplinaire et international}

2 L'ambition de ce colloque vise à réaliser l'état de l'art le plus pluridisciplinaire possible sur « Les oiseaux chanteurs ». Il s'agit d'un colloque prospectif. S'inscrivant à la croisée des sources et des regards scientifiques, ce colloque cherche à mettre en présence des chercheurs issus d'horizons disciplinaires fort divers et éloignés, tant des sciences humaines et sociales que des sciences de la vie, intéressés par les différentes définitions des "chants" des oiseaux, en vue de construire un objet de recherche commun. L'objectif est de faire dialoguer, dans l'interdisciplinarité, anthropologues, 
ornithologues, éthologues, archéologues, environnementalistes, littéraires, linguistes, philologues, historiens, historiens de l'art, psychologues de la musique et de la cognition et musicologues.

Le colloque sera consacré à 2 axes thématiques :

- $1^{\text {er }}$ axe de définition du sujet: "Savoirs scientifiques et savoirs communs d'hier et d'aujourd'hui »;

- $2^{\mathrm{e}}$ axe : «Des oiseaux chanteurs et des sociétés : les liens sociaux dans le temps et les espaces».

\section{Organisation, date et lieu}

Le colloque se tiendra en Bourgogne, sur trois jours, les 4, 5 et 6 avril 2012, sur l'un des sites de l'UMR ARTeHIS, au Centre archéologique européen de Bibracte à Glux-enGlenne (Nièvre). Les frais d'hébergement et de repas des intervenants seront pris en charge, sauf les frais de transport. Des conditions particulières sont réservées aux doctorants. Leurs frais seront pris en charge. La durée de chaque communication sera de 30 minutes avec la discussion. Le lieu en pleine nature, ainsi que les trois journées consécutives laisseront du temps pour échanger et discuter. Pour favoriser les découvertes, un concert et une conférence du soir autour des oiseaux chanteurs, ainsi qu'une balade ornithologique dans les bois du Morvan sont prévus.

\section{Calendrier de l'appel à communications}

5 L'appel porte aussi bien sur des communications que sur des posters de présentation:

- du 5 juin au 30 juin 2011 : information sur le colloque de 2012.

- du 30 juin au 15 octobre 2011 : ouverture des propositions. Elles doivent comporter le titre de la communication, un résumé de 300 mots, 5 mots-clés et une bio-bibliographie (identité, court CV, publications principales) ;

- fin novembre 2011 : réponses du Comité scientifique.

6 Les propositions de communication sont à envoyer à Corinne Beck (cbeck16@wanadoo.fr) ou à Martine Clouzot (martine.clouzot@wanadoo.fr).

7 Pour plus d'informations: http://www.artehis-cnrs.fr/IMG/pdf/ appel_a_communication_oiseaux_chanteurs.pdf

INDEX

Mots-clés : oiseau chanteur 